\title{
AN INVESTIGATION AND RECTIFICATION ON FAILURE OF BEARINGS OF CASTING SHAKEOUT USED IN FOUNDRY INDUSTRIES
}

\author{
S.N. Aloni ${ }^{1}$, N.D. Dhote ${ }^{2}$, T.G. Lokhande ${ }^{3}$, D.G. Madiwale ${ }^{4}$ \\ ${ }^{1}$ Asst. Professor, Mechanical Engineering Department, D.M.I.E.T.R.Wardha, Maharashtra, India \\ ${ }^{2}$ Asst. Professor, Mechanical Engineering Department, D.M.I.E.T.R.Wardha, Maharashtra, India \\ ${ }^{3}$ Asst. Professor, Mechanical Engineering Department, D.M.I.E.T.R.Wardha, Maharashtra, India \\ ${ }^{4}$ Sr. Design Engineer, Design Department, SPAN Filtermist India Pvt. Ltd. Pune, Maharashtra, India
}

\begin{abstract}
This project deals with investigation and rectification on failure of bearing of casting shakeout, required in foundry industries to separate solidified casting and sand from mould box. The failure of bearings is mainly due to brinelling tends to create cavities on the bearing raceway. This result in roller and inner races surface of spherical bearing get damage. The rectification of existing system uses four bearings as modified setup of existing system to distribute the load acting on shakeout aims at reducing this frequent breakdown, increases life of bearings and increases the productivity of plant. The software Pro-E wildfire 4 is used for modeling.
\end{abstract}

Keywords: Brinelling, Casting shakeout, Spherical Roller bearing, and Bearing life

\section{INTRODUCTION}

In the present scenario, manufacturing units in India are having large share among the manufacturing industries, engaged in production of variety of products including Automobile, Electrical, Textiles and many others. If we look at these industries, it is seen that these industries are playing very important role in development and production of many products required for particular application and make them available to customers. The various casting component required for automobiles such as Cylinder Heads, Engine Blocks, Gear Boxes, Differentials, Brake Drums, Crank Cases, and Rotor Discs etc are produced by foundries. A foundry is a factory that produces metal casting. Metals are cast into shapes by melting them into a liquid, pouring the metal in a mold, and removing the mould material or casting after the metal has solidified as it cools. The common processes in foundry are shown in Flow chart as shown in figure 1.1 .

$* * *$

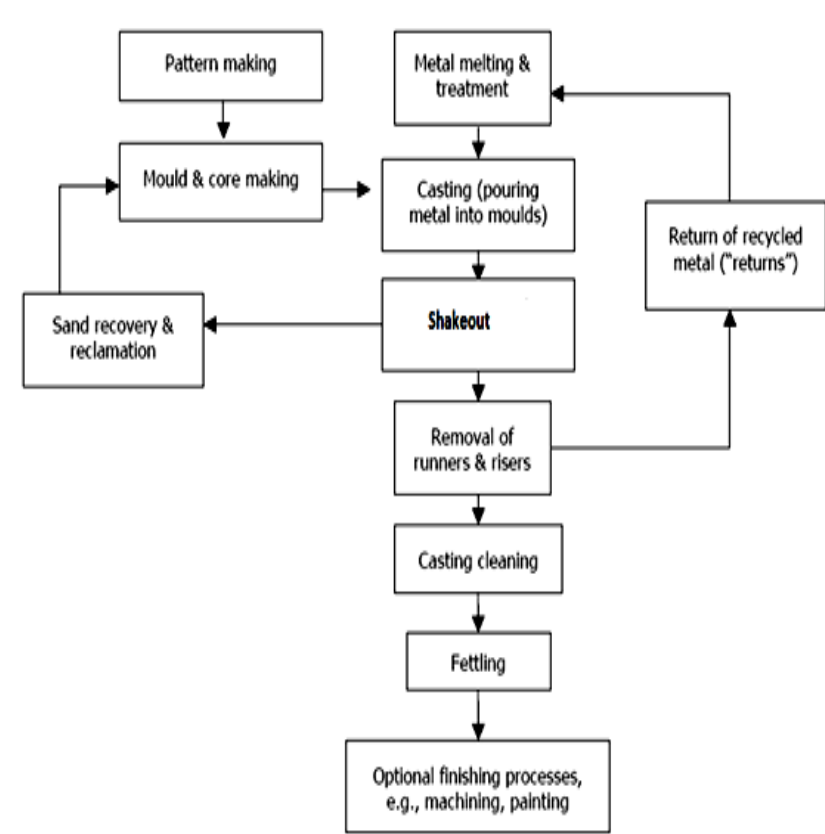

Fig. 1.1: Flow Chart of a Typical Foundry Process

\subsection{Shakeout used at Foundry Industries}

Shakeout is process used to separate sand and casting from mould box after solidification when mould box placed over the vibrating deck of shakeout. The casting remains over the vibrating deck and sand fall down through holes provided on vibrating deck. The hopper with belt conveyors is placed below the vibrating deck. So belt conveyors transfer sand to sand plant. 


\section{REVIEW OF LITERATURE}

Designers concern to use rolling element bearings at industrial equipments applications depending upon higher bearing life and load carrying capacity. The industrial equipments are subjected to different type of loading and atmospheric conditions results in failure of bearings.

R.K. Upadhyay, L.A. Kumaraswamidhas and Md.Sikandar Azam [1], Rolling Contact Fatigue (RCF) occurs due to the result of cyclic stresses developed during operation and mechanism that involve in fretting failure of rolling element bearing. As bearing raceways of non-rotating rolling element bearings exposed to vibration or sliding oscillation false Brinelling occurs. Bearing surface due to false Brinelling tends to damage within a short period, due to cavities created on the bearing raceway. Recommendation towards enhancement of bearing life is also suggested.

D. Azad and K. Ramji [3], the detection of faults in the industrial systems such as fans are integral components of many industrial plants, particularly Steel plants, power plants, paper and printing, automotive, Air conditioning, petro chemical plants. Fans are normally mounted in bearing-housing assembly, where fan failure can cause expensive unscheduled plant shutdowns. Early detection of faults in these systems allows the user to initiate repairs and it can prevent costly maintenance.

N.S. Jammu and P.K. Kankr [4], described the presence of faults in bearings results in severe vibrations of rotating machinery. Timely detection of these faults and estimation of the time to failure are the areas of concern for researchers because abrupt failure of bearings may cause malfunctioning of the entire system and this result in downtime for the system and economic loss to the customer. Jyoti K. Sinha [10], describes several vibration based methods are used in practice to identify the fault in the antifriction bearings (ball bearings and roller bearings), however experience suggests that these methods are just indicative to the bearing health and not sufficient to identify the root cause if the failure is premature and frequent. Many rotating machines have rotors that are supported through anti-friction ball or roller bearings. A photograph of a typical premature failed roller bearing is shown in Figure 2.1.

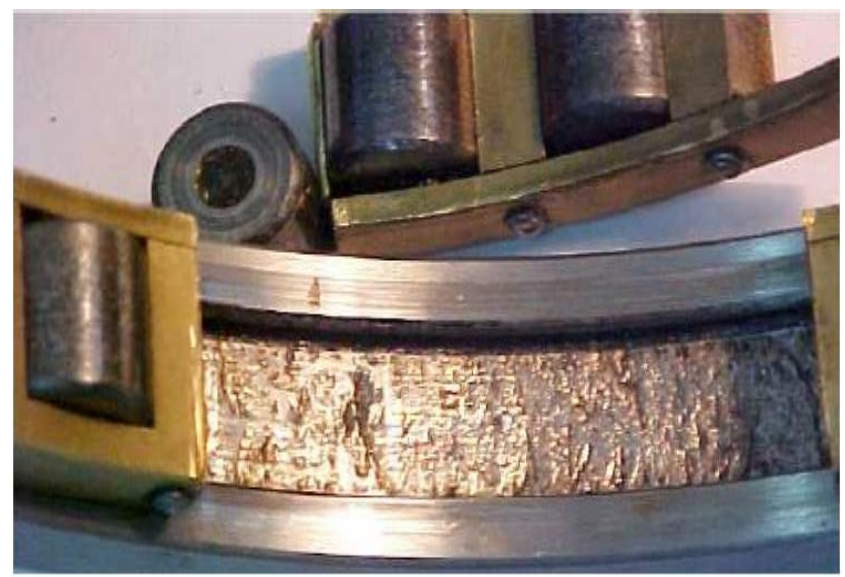

Fig. 2.1: Photograph of a premature failed bearing
F. Camci, K. Medjaher, N. Zerhouni, P. Nectoux [6], discussed rolling element bearing failure is one of the foremost causes of breakdown in rotating machinery. It is not uncommon to replace a defected/used bearing with a new one that has shorter remaining useful life than the defected one. Thus, prognostics of bearing plays critical role for increased availability and reduced cost.

B. A. Kardile [7], This study work is proposed to carry out vibration analysis of heavy duty centrifugal Blowers \& bearing failure analysis. The vibration analysis of the heavy duty centrifugal blower gives the results as the bearing life is depends upon

1] The bearing characteristic number, ZN/P

2] Running condition-Temperature \& RPM under which the machine runs

3] Bearing load condition as static \& dynamic load Carrying capacity

4] Clearance between roller \& outer race

5] Heat dissipation capacity of the plumber block \& other accessories

6] Lubrication frequency \& standard of lubricant.

Generally the vibration parameters as displacement \& velocity are depends upon the bearing wear of outer race because of roller hits on surface of the race at high temperature.

\section{PROBLEM FORMULATION}

Especially in foundry industry, insufficient awareness and use of technology, and new design features can cause problems such as breakdown. Failure of the machinery devices is one of the major problems in foundry industry.

In the present work the investigation is carried out to identify the type of failure in the spherical roller bearing of casting shakeout subjected to static and dynamic loads. The dynamic load i.e. sudden or impact load due to weight of casting and mould box and almost equal to static load.

\section{AIM \& OBJECTIVE}

To identify type of failure in spherical roller bearing of casting shakeout following points are taken into consideration.

- Detail study of working of existing shakeout.

- Detail study of load acting on spherical roller bearing.

- Investigation of spherical roller bearing failure by visual examination, analytically calculation of bearing life.

- Modeling and simulation of existing setup of shakeout.

- Find out the strength of spherical roller bearings for existing setup by stress analysis in ANSYS software.

- $\quad$ Suggesting modification in existing setup and modeling of modified setup.

- Find out the strength of spherical roller bearings for modified setup by stress analysis in ANSYS software.

- Detailed comparison of existing setup and newly modified proposed setup. 


\section{WORK DONE}

\subsection{Investigation on Failure of Spherical Roller}

\section{Bearing of Casting Shakeout}

The casting shakeout in foundry industry is used to separate casting and sand from the mould box. The Failure of bearing causes stoppage of shakeout, this results in stoppage of moulding line. It affect the production of foundry industry i.e. increase in idleness of operators working on moulding line also increase in downtime of production.

The shakeout is investigated for failure of bearing. The damage bearing removed from shakeout is visually inspected and it is observed that some dent marks are occurs on a roller periferical surface and inner races also. This is due to excessive impact load acting during shakeout operation such type of failure is brinelling failure.

\subsection{Construction of Casting Shakeout}

The shakeout consist of parts 1 - Counter mass of $63 \mathrm{~kg}$ driven by $30 \mathrm{Hp}$ motor with $960 \mathrm{rpm}, 2$ - Vibrating deck having vibrating span of 10 to $15 \mathrm{~mm}, 3$ - Bottom Base, 4Shaft having $110 \mathrm{~mm}$ dia., 5- Bearing of type 22322 (Roller spherical bearing), 6- Spring.

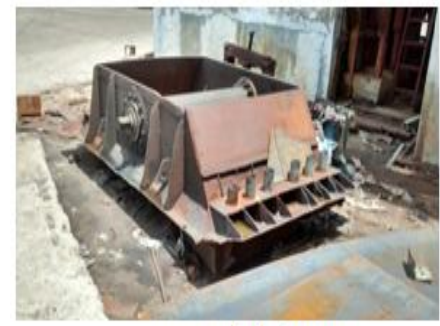

Inverted Shakeout

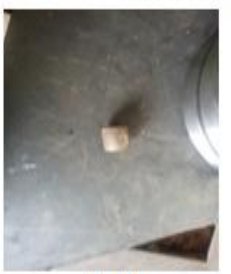

Roller

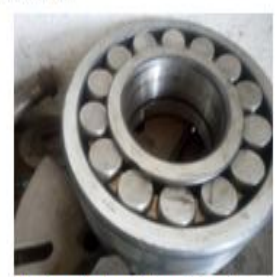

Spherical roller Bearing

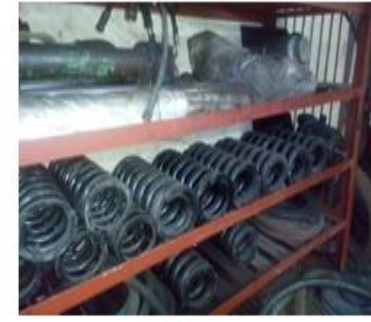

Springs

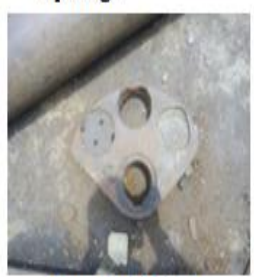

Counter Weight
Fig. 5.2: Details of shakeout parts and Bearings

In shakeout process, the casting and mould are kept on vibrating deck with jerk. Due to vibrations of deck, sand is separated from casting. After the separation, sand is processed to sand plant through hopper which is fixed below the casting mould vibrating screen to the conveyor. The bearings used in shakeout causes failure.
Table -1: Specifications of Shakeout

\begin{tabular}{|c|l|l|}
\hline \multicolumn{1}{|c|}{ Particulars } & \multicolumn{2}{|c|}{ Single shaft of 2 spherical roller bearings } \\
\hline \multirow{4}{*}{ Overall dimensions } & Overall Length & $2730 \mathrm{~mm}$ \\
\cline { 2 - 3 } & Overall Width & $1620 \mathrm{~mm}$ \\
\cline { 2 - 3 } & Overall Height & $620 \mathrm{~mm}$ \\
\hline \multirow{5}{*}{ Load Capacity } & Body weight & $1000 \mathrm{Kg}$ \\
\cline { 2 - 3 } & Mould box and sand Weight & $600 \mathrm{Kg}$ \\
\cline { 2 - 3 } & Casting weight & \\
\cline { 2 - 3 } & Shaft weight & $200 \mathrm{Kg}$ \\
\cline { 2 - 3 } & Gross weight & $200 \mathrm{Kg}$ \\
\cline { 2 - 3 } & Counter mass weight & $2000 \mathrm{Kg}=19.62 \mathrm{KN}$ \\
\hline \multirow{5}{*}{$\begin{array}{l}\text { (Two no.) } \\
\text { Motor }\end{array}$} & RPM & $63 \mathrm{Kg}=618.03 \mathrm{~N}$ \\
\cline { 2 - 3 } & Power & $960 \mathrm{rpm}$ \\
\hline \multirow{2}{*}{$\begin{array}{l}\text { (22322) (Two no.) } \\
\text { Spherical Roller Bearings }\end{array}$} & Inner Races Diameter & $110 \mathrm{~mm}$ \\
\cline { 2 - 3 } & Outer Races Diameter & $240 \mathrm{~mm}$ \\
\cline { 2 - 3 } & Width & $80 \mathrm{~mm}$ \\
\hline
\end{tabular}

\subsection{Working of Casting Shakeout}

Motor drives the shakeout shaft through Universal joint. Rotation of this shaft causes rotation of counter masses fixed on both end of shaft exerts centrifugal force on the deck in the vertical plane and this causes the vibration of deck as shown in figure 5.3. The casting shakeout used in foundry industries works on the principle of eccentric masses to vibrate shakeout deck. The casting shakeout consists of two spherical roller bearings fixed in shakeout body with bearing casing. The shaft is aligned with bearing using proper interference. Two counter masses are attached at both extreme end of shaft. The whole assembly is mounted on springs (shown in Fig. 5.3).

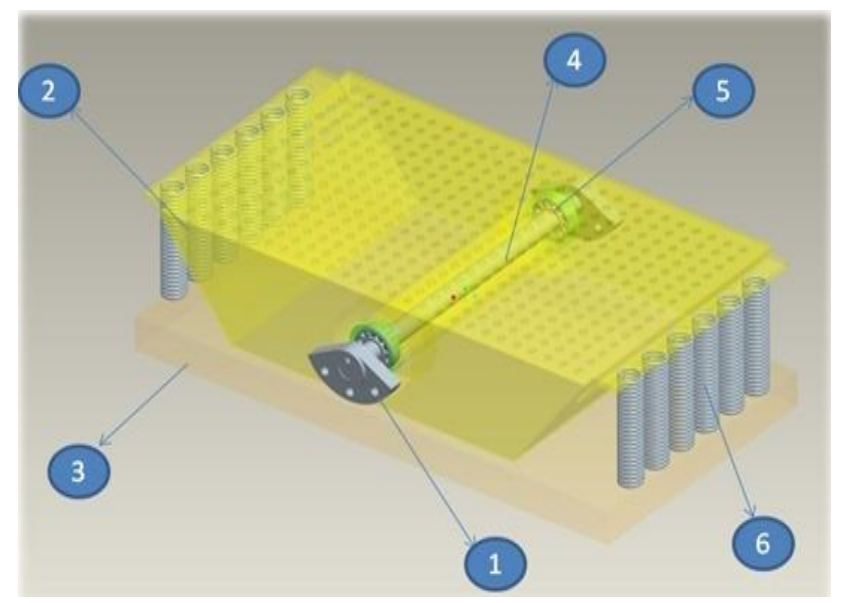

Fig. 5.3: Existing Casting Shakeout

The one end of shaft is universally coupled with motor, when torque is applied to shaft it rotates counter masses, generates centrifugal force which try to vibrate deck in horizontal and vertical plane initially, when increases the rpm it vibrate in vertical plane only with vibrating amplitude. During shakeout operation the jerk is given by operator by placing casting and mould box rapidly on deck. Out of total load $70 \%$ load is transferred to spring and $30 \%$ load to bearing. 


\subsection{Calculation for Bearing Life}

Equivalent Bearing Load P $(\mathbf{k N})$ :

$$
\mathrm{P}=\left(\mathrm{XF}_{\mathrm{r}}+\mathrm{YF}_{\mathrm{a}}\right) \mathrm{K}_{\mathrm{g}} \mathrm{K}_{\mathrm{o}} \mathrm{K}_{\mathrm{p}} \mathrm{K}_{\mathrm{r}}
$$

Where $\mathrm{F}_{\mathrm{r}}=$ Radial Load $(\mathrm{kN}), \mathrm{F}_{\mathrm{a}}=$ Axial Load $(\mathrm{kN}), \mathrm{X}, \mathrm{Y}=$ Constant values selected from table, $\mathrm{K}_{\mathrm{s}}=$ Service Factor, $\mathrm{K}_{\mathrm{o}}$ = Oscillation Factor, $\mathrm{K}_{\mathrm{p}}=$ Preloading Factor, $\mathrm{K}_{\mathrm{r}}=$ Rotational Factor, from Design Data Book

\section{Radial Load Fr (KN):}

$$
F_{\mathrm{r}}=\left(\frac{\mathrm{fG}_{1} \mathrm{GR} \omega^{2}}{\mathrm{~S}\left(\mathrm{G}+\mathrm{G}_{1}\right)}\right)
$$

Where $\mathrm{f}=$ Application factor, $\mathrm{S}=$ Number of bearings $\mathrm{G}=$ mass of body $(\mathrm{kg}) \mathrm{G} 1=$ Mass of counter weight $(\mathrm{kg}), \mathrm{R}=$ Distance of C.G. of counter weight from axis of bearing.

\section{Life of Bearing (in million cycles):}

$$
\mathrm{L}=\left(\frac{\mathrm{C}}{\mathrm{P}}\right)^{\mathrm{n}} * \mathrm{~K}_{\mathrm{ret}}
$$

Where $\mathrm{L}=$ Life in million cycles, $\mathrm{C}=$ Dynamic load capacity $(\mathrm{KN}), \mathrm{P}=$ Equivalent Bearing Load $(\mathrm{KN}), \mathrm{n}=3.33$ for roller bearing, Kret $=$ Reliability factor select from table

\section{Life of Bearing (in hours):}

$$
\mathrm{L}(\text { in hours })=\left(\frac{10^{6} \mathrm{~L}(\text { in million cycles })}{60 \mathrm{~N}}\right)
$$

Where, $\mathrm{N}=$ Rotational speed in $\mathrm{rpm}$

Life of Bearing (in days):

$$
\mathrm{L}(\text { in days })=\left(\frac{\mathrm{L} \text { (in hours })}{24}\right)
$$

Table -2: Bearing Life of Existing Setup

\begin{tabular}{|l|l|}
\hline \multicolumn{1}{|c|}{ CONTENT } & \multicolumn{1}{c|}{ VALUES } \\
\hline $\mathrm{K}_{\mathrm{O}}$ & 1 \\
\hline $\mathrm{K}_{\mathrm{D}}$ & 1.5 \\
\hline $\mathrm{K}_{\mathrm{r}}$ & 1 \\
\hline $\mathrm{P}$ & $289.97 \mathrm{kN}$ \\
\hline $\mathrm{C}$ & $950 \mathrm{kN}$ \\
\hline $\mathrm{n}$ & 3.33 \\
\hline $\mathrm{K}$ ret & 1 \\
\hline $\mathrm{L}$ & $52.022 \mathrm{million}$ cycles \\
\hline $\mathrm{N}$ & $960 \mathrm{rpm}$ \\
\hline $\mathrm{L}$ in Hr & $903.153 \mathrm{Hrs}$ \\
\hline L in Days & 37.63 Days \\
\hline
\end{tabular}

\subsection{Modified Setup}

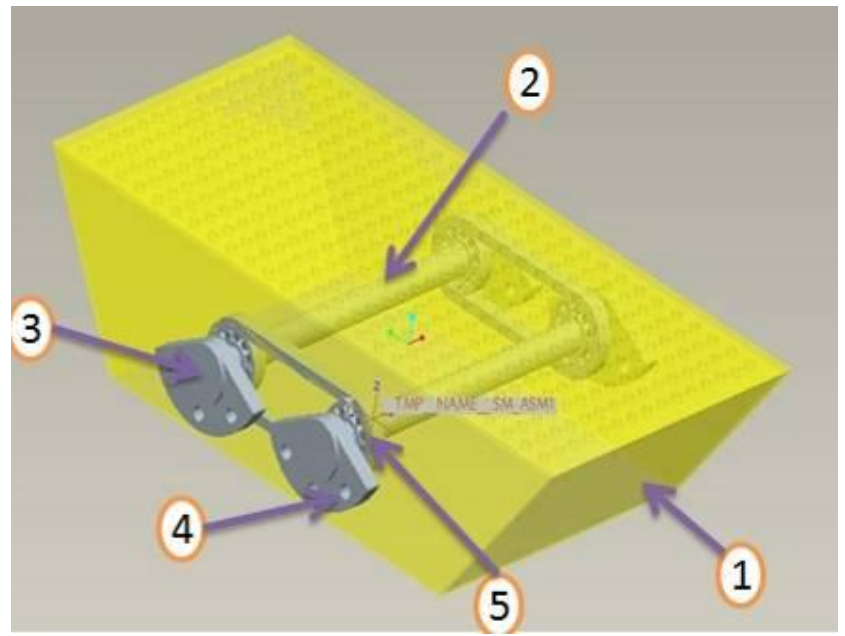

Fig. 5.5: Parts of Modified Setup Shakeout

Where, 1- Body of shakeout, 2- Shafts with two numbers driven by two $960 \mathrm{rpm}$ motors, 3- Cap to counter weight assembled on shafts, 4- Counter weight with four numbers having same weight $63 \mathrm{Kg}, 5$ - Spherical roller bearings of type 22322 with four numbers.

\subsection{Working of Modified Shakeout}

The working of modified setup is same as that of existing shakeout i.e. two motors drive the shakeout shafts through Universal joints in opposite direction as shown in figure. Rotation of this shaft causes rotation of counter masses fixed on both end of shaft exerts centrifugal force on the deck in the vertical plane and this causes the vibration of deck only in vertical plane as shown in figure 5.5 and figure 5.6.

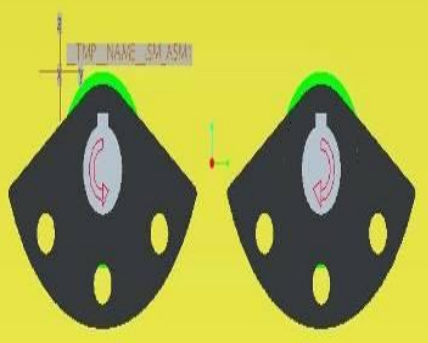

Fig. 5.6: Direction of rotation of shaft during shakeout 
Table -3: Bearing Life of Modified Setup

\begin{tabular}{|l|c|}
\hline \multicolumn{1}{|c|}{ CONTENT } & VALUES \\
\hline $\mathrm{K}_{\mathbb{Q}}$ & 1 \\
\hline $\mathrm{K}_{\mathrm{Q}}$ & 1.5 \\
\hline $\mathrm{K}_{\mathrm{r}}$ & 1 \\
\hline $\mathrm{P}$ & $144.98 \mathrm{kN}$ \\
\hline $\mathrm{C}$ & $950 \mathrm{kN}$ \\
\hline $\mathrm{n}$ & 3.33 \\
\hline $\mathrm{K}$ ret & 1 \\
\hline $\mathrm{L}$ & 523.26 million cycles \\
\hline $\mathrm{N}$ & $960 \mathrm{rpm}$ \\
\hline $\mathrm{L}$ in Hr & $9083.24 \mathrm{Hrs}$ \\
\hline L in Days & 378.46 Days \\
\hline
\end{tabular}

\section{RESULT \& DISCUSSION}

This project work addresses live problem of failure of shakeout bearing at Foundry Industries ltd. As per visual inspection and load consideration the type of shakeout bearing failure is brinelling. This failure can be rectified with increase in bearing life using modified setup. Life of bearing in modified setup is calculated analytically and it is found ten times more than that in existing setup. It saves cost of annual production loss, reduces breakdown time. The new setup is modeled and analysis is carried out with same software it is found that deformation and stresses are less in modified setup.

Table -4: Comparisons of bearing life and annual production loss of Existing and modified setup

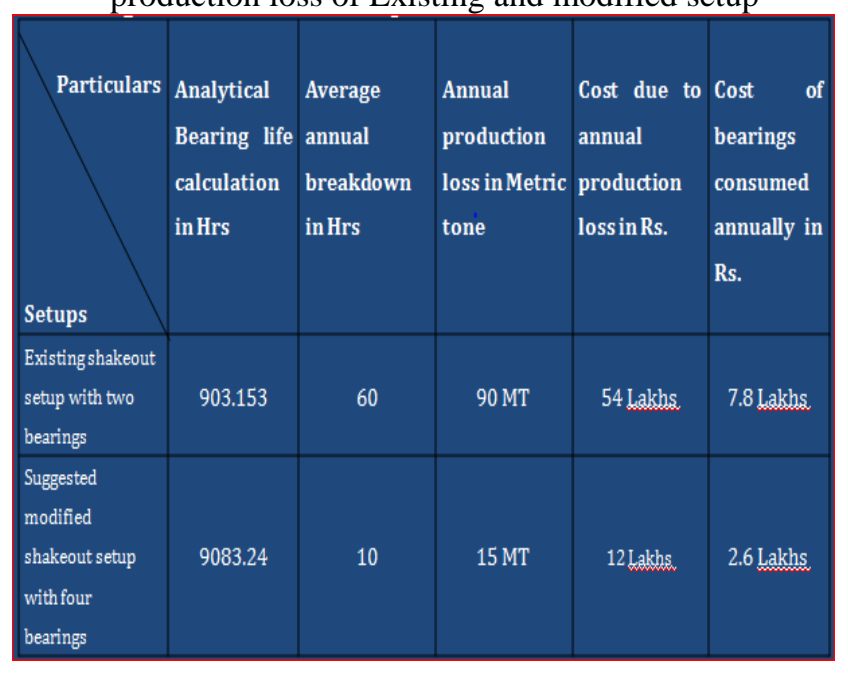

\section{CONCLUSION}

In this project work, investigation on bearing failure of shakeout used in foundry industry is performed. After investigation, it is revealed that, the failure of bearing mainly occurs because of impact load acting repeatedly and is brinelling. This reduces life of bearings. The modifications are suggested in existing set up, which improve the bearing life ten times than that of in existing setup.

\section{REFERENCES}

[1] R. K. Upadhyay, L .A. Kumaraswamidhas and Md.Sikandar Azam, "Rolling element bearing failure analysis: A case study," in elsevier, (2013), pp. 1517.

[2] P. G. Kulkarni and A. D. Sahasrabudhe, "Application Of Wavelet Transform For Fault Diagnosisof Rolling Element Bearings," in IJSTR, vol. 2, issue 4, April 2013, pp. 138-148.

[3] D. Azad and K. Ramji, "Identification of bearing assembly defects using Finite Element Analysis and Condition Monitoring Techniques," in IJERT, Vol. 1 Issue 6, August - 2012, pp. 1-13.

[4] N.S. Jammu and P.K. Kankar, "A Review on Prognosis of Rolling Element Bearings" in IJEST, Vol. 3 No.10 October 2011, pp. 7503-7497.

[5] Katsuyuki Kida, Takashi Honda and Edson Costa Santos, "Semi-circular surface cracks and flaking failures in silicon nitride bearings," Published online by the VBRI press in 2011, pp. 336-340.

[6] F. Camcia, K. Medjaherb, N. Zerhounib and P. Nectouxb, "Feature Evaluation for Effective Bearing Prognostics," published in "Quality and Reliability Engineering International", 2012, pp. 1-15

[7] B. A. Kardile, "Bearing Life Improvement of Centrifugal Blowers by Vibration Analysis," in IJMER, Vol.2, Issue.6, 2012, pp. 4026-4029.

[8] J Halme and P Andersson, "Rolling contact fatigue and wear fundamentals for rolling bearing diagnostics - state of the art," Proc. IMechE Vol. 224 Part J: J. Engineering Tribology, 2009, pp. 377-393.

[9] Dr. H. Hirani, "Failure of Rolling Bearings: An Overview"

[10] Jyoti K. Sinha, "Frequent And Premature Failure Of Anti-Friction Bearings: Diagnosis Approach?" 3rd International Conference on Integrity, Reliability and Failure, Porto/Portugal, 20-24 July 2009, pp. 1-8.

[11] Mario Ricci, "Ball Bearing Subjected to Various Eccentric Loads," in Dincon' 8th Brazilian conference on Dynamics control and applications,2009, pp. 1-7.

[12] Dr. Rajendra Karwa, "A Textbook of Machine Design," 2010.

[13] Robert L. Norton, "Machine Design an Integrated Approach," Pearson, second edition, 2012, pp. 653665

[14] Dr. S.S. Wadhwa and Er. S.S. Jolly, "Machine Design a Basic Approach" Dhanpat Rai, 3rd Edition, 2012, pp. 583-604.

[15] V. B. Bhandari, "Machine Design Data Book," McGraw Hill, 2014, pp. 15.1-15.66.

[16] B. D. Shiwalkar, "Design Data For Machine Elements S.I.Units,” Denett, 2011, pp. 125-149. 


\section{BIOGRAPHIES}

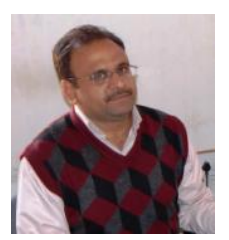

Prof. S. N. Aloni, Asst. Prof. In Mechanical Engineering Department, D.M.I.E.T.R., Wardha.

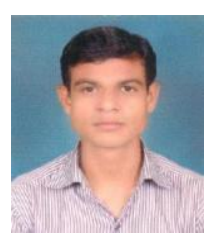

Prof. N.D. Dhote, Asst. Prof. In Mechanical Engineering Department, D.M.I.E.T.R., Wardha.

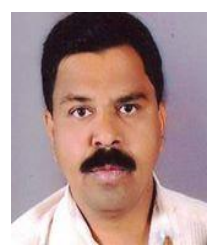

Prof. T.G. Lokhande, Asst. Prof. In Mechanical Engineering Department, D.M.I.E.T.R., Wardha.

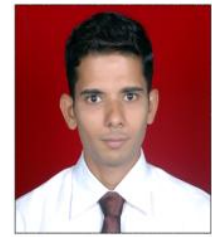

Mr. D. G. Madiwale, Sr. Design Engineer, SPAN Filtermist India Pvt. Ltd. Pune. 